\title{
Factorial design approach to fabricate and optimize floating tablets based on combination of natural polymer and rice bran wax
}

Vidya P. Sabale * (D) and Gunjan G. Gadge

\begin{abstract}
Background: The aim of the present research work was to fabricate a novel gastroretentive drug delivery system in the form of tablets using a combination of natural polymer and rice bran wax with an intention to control drug delivery and to enhance the gastric residence time of the model drug Famotidine in the gastrointestinal tract.

Results: The results of the preliminary trial batches prepared by using the hot melt granulation technique resulting in six different formulations showed good physicochemical characteristics and tablets conformed to the Pharmacopoeial specifications. Gastroretentive tablets containing natural polymer showed prolonged drug release comparable to Methocel. The optimized formulation (C3) using $3^{2}$ factorial design showed FLT $27 \pm 2.47$ s, SI $92.68 \pm 1.36 \%$ and \% CDR $98.89 \pm 0.39 \%$ at $12 \mathrm{~h}$. The stability studies indicated the stability of the formulation during storage.

Conclusions: It was concluded that the release profile fitted best to zero-order equation with non-Fickian diffusion mechanism of drug release which demonstrates swelling-controlled drug release mechanism. Thus, the formulated tablets have the potential for improved release and gastroretentive properties.
\end{abstract}

Keywords: Gastroretentive, Natural polymer, Rice bran wax, Factorial design, Drug release, Swelling index 


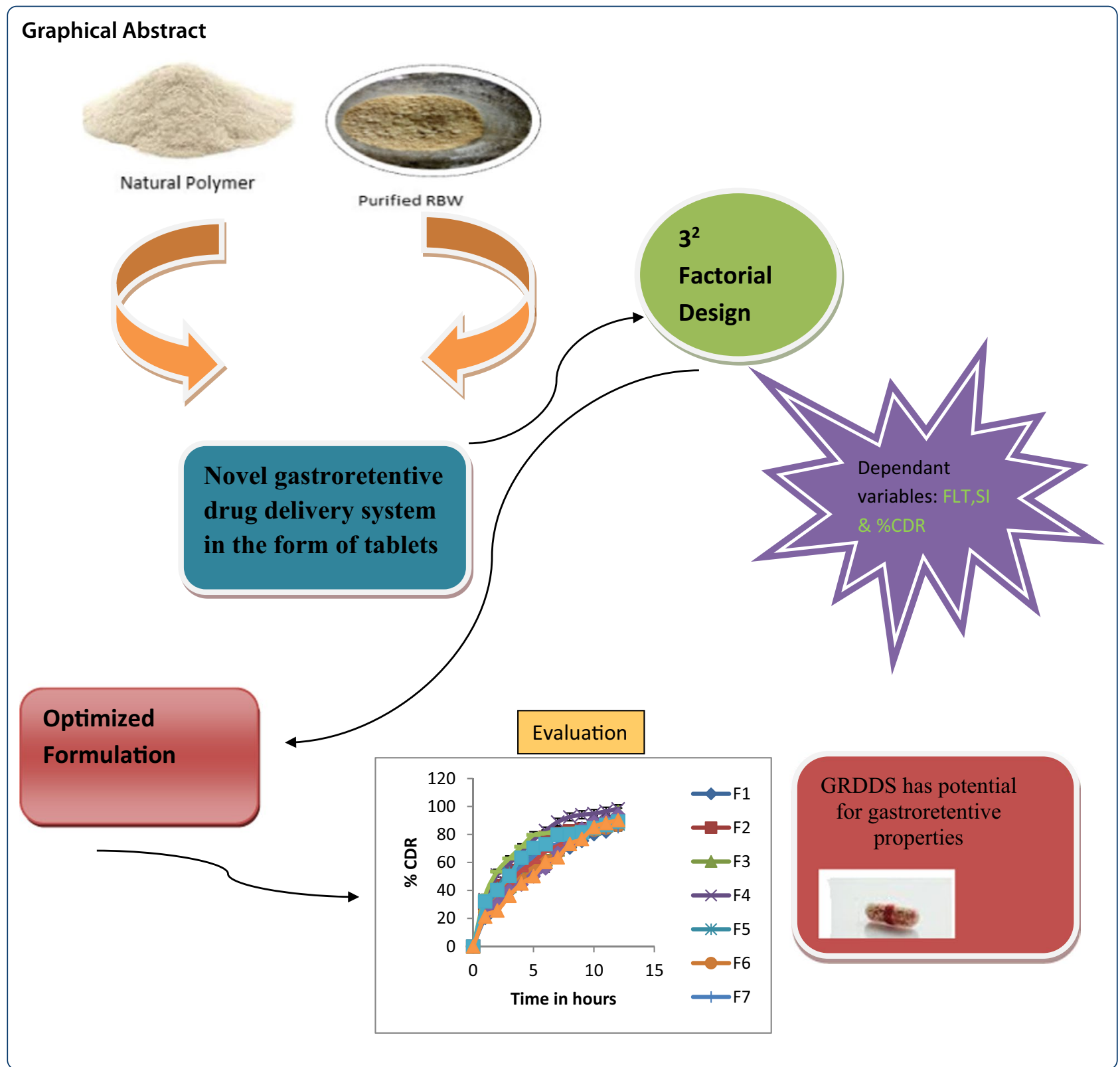

\section{Background}

The oral route is the most versatile, convenient and normally employed route of drug delivery for systemic action [1]. Controlled release drug delivery by oral route is widely used because of its easy administration, patient suitability and formulation changeability [2]. To achieve the suitable therapeutic activity, frequent dosing of drugs is necessary. Several attempts are being made to reduce dosing frequency of a drug delivery system providing therapeutically effective plasma drug concentration for a longer period of time in a controlled and reproducible manner [2, 3]. In the upper gastrointestinal tract (GIT), for achieving, local or systemic effects, gastroretentive drug delivery system (GRDDS) can be used to prolong the residence time of the drug and also to target the sitespecific drug release. Prolonged gastric retention by these systems may improve bioavailability and dissolution for drugs that are less soluble in a high $\mathrm{pH}$ environment, provided that the drug is stable in gastric environment $[4,5]$.

Drug absorption in the GIT depends upon the factors such as gastric emptying process, the gastrointestinal transit time of dosage forms, drug release from the dosage form and site of drug absorption [6]. A drug must be in a solubilized and stable form to successfully cross the biological barrier. As the drug travels through the GIT, its $\mathrm{pH}$ ranges from 1 to 8 [7]. 
Famotidine was used as a model drug which is a potent histamine H2-receptor antagonist. It is widely used in the treatment and prevention of gastric ulcers, duodenal ulcers, Zollinger-Ellison syndrome and gastroesophageal reflux disease. Poor absorption, less bioavailability and short half life of Famotidine after oral administration helped the development of a controlled release formulation $[8,9]$.

Natural gums are polysaccharides consisting of numerous sugar units such as glucose, galactose, rhamnose, arabinose, xylose, mannose and uronic acids. Due to their availability, safety and biodegradability, they are preferred over synthetic polymers. The majority of the gums are safe enough to be consumed and are hence, widely used in the field of drug delivery and as food additives [10].

Guar gum is obtained from the seeds of the plant Cyamopsis tetragonoloba, family: Leguminosae [11-13]. Guar gum hydrates readily in aqueous media to produce a viscous pseudoplastic solution that has greater low shear viscosity than the other hydrocolloids [14, 15].

The polymer and wax are commonly used as matrixforming components. The use of wax seems to have a particular advantage due to chemical inertness against other materials, good stability varying at $\mathrm{pH}$ and moisture levels and well-established safe application in humans being [16].

The source of rice bran wax (RBW) is Oryza sativa belonging to family Graminae which is available plentifully. It is an important by-product of the rice bran oil industry. RBW is used as binding agent, plasticizer, coating and gelling agent. It is also used in cosmetics and in foods as a thickener [16, 17].

The objective of the present work was to formulate floating tablets for increased residence time in the stomach and also for controlling drug delivery using natural polymer (bioadhesive) and RBW (release retardant).

\section{Methods}

\subsection{Materials}

Famotidine as a gift sample was supplied by Cipla, Goa. Crude RBWwas obtained from Maheshwari Solvent Extraction Plant, Gondia, Maharashtra, India. Guar gum was purchased from Merck Specialities Pvt. Ltd., Mumbai, and all other excipients used were of analytical grade.

\subsection{Purification and characterization of RBW}

RBW was purified and characterized for further use in the study [16-19].

\subsection{Compatibility study}

Mixtures consisting of different ratios of drug/RBW, drug/polymer and either drug or RBW/polymer alone were subjected to FTIR analysis using a model IR Affinity-1S FTIR spectrophotometer (Shimadzu Corporation Kyoto, Japan).

\subsection{Formulation of gastroretentive tablets containing natural polymer, methocel K4M and RBW (preliminary trial batches)}

For the formulation of gastroretentive tablets, the six different preliminary trial batches were prepared (Table 1) each containing Famotidine as a model drug (40 mg) and by varying the concentration of polymer (20 mg, $25 \mathrm{mg}, 30 \mathrm{mg}$ ) and RBW (15 mg, $20 \mathrm{mg}, 25 \mathrm{mg}$ ). Melt granulation technique was used for the preparation of gastroretentive tablets [20]. The tablets $(250 \mathrm{mg})$ were prepared by direct compression method using flat-faced 6-mm punch (Rimek Mini Press-I machine).

Table 1 Preliminary trial batch composition containing HPMC K4 M and RBW, guar gum and RBW

\begin{tabular}{|c|c|c|c|c|c|c|}
\hline \multirow[t]{2}{*}{ Ingredients } & \multicolumn{6}{|c|}{ Quantity per mg Tablet (mg) } \\
\hline & HF1 & HF2 & HF3 & GF1 & GF2 & GF3 \\
\hline Famotidine & 40 & 40 & 40 & 40 & 40 & 40 \\
\hline RBW & 25 & 15 & 20 & 25 & 15 & 20 \\
\hline HPMC K4 M & 20 & 25 & 30 & - & - & - \\
\hline Guar gum & - & - & - & 20 & 25 & 30 \\
\hline Ethyl cellulose & 10 & 10 & 10 & 10 & 10 & 10 \\
\hline Sodium bicarbonate & 7.5 & 7.5 & 7.5 & 7.5 & 7.5 & 7.5 \\
\hline Magnesium stearate & 1 & 1 & 1 & 1 & 1 & 1 \\
\hline Talc & 2 & 2 & 2 & 2 & 2 & 2 \\
\hline Lactose & 144.5 & 149.5 & 139.5 & 144.5 & 149.5 & 139.5 \\
\hline Total Weight & 250 & & & & & \\
\hline
\end{tabular}




\subsection{Evaluation of gastroretentive tablets containing natural polymer, methocel K4M and RBW (preliminary trial batches)}

The prepared tablets were evaluated for precompression and post-compression parameters [21-23].

\subsection{In vitro buoyancy}

Floating lag time (FLT) and total floating time (TFT) were considered as in vitro buoyancy. The tablets were placed in a 100-ml beaker containing $0.1 \mathrm{~N} \mathrm{HCl}$, which was maintained at $37^{\circ} \mathrm{C}$. The time required for the tablet to rise to the surface of the medium was determined as the buoyancy lag time or FLT. The total buoyancy time or total floating time was considered as the time duration for which the dosage form remained floating on the surface of medium $[24,25]$.

\subsection{Swelling index (\%)}

The tablets were weighed individually and placed separately in Petri dish containing $5 \mathrm{ml}$ of $0.1 \mathrm{~N} \mathrm{HCl}$ and incubated at $37{ }^{\circ} \mathrm{C} \pm 10{ }^{\circ} \mathrm{C}$. At regular 2-h time intervals until $12 \mathrm{~h}$, the tablets were removed from Petri dish, and the excess surface liquid was removed carefully using the tissue paper. After draining free water by blotting with tissue paper, these were weighed for weight gain on the analytical balance [26, 27]. The following formula was used for calculating swelling index (SI):

Swelling Index $=($ weight of tablet at time-weight of tablet before immersion)/ (weight of tablet before immersion) $\times 100$.

\subsection{In vitro dissolution studies}

The in vitro dissolution of all the batches were carried out in $0.1 \mathrm{~N}$ hydrochloric acid $(\mathrm{HCl})$ as the dissolution medium using USP Type II Apparatus at $50 \mathrm{rpm}$ and maintaining the temperature at $37 \pm 0.5{ }^{\circ} \mathrm{C}$. The dissolution was carried out for $12 \mathrm{~h}[28,29]$.

\subsection{Formulation of gastroretentive tablets containing natural polymer and RBW using $3^{2}$ full factorial design}

An optimization for the prepared buccoadhesive tablets were carried out using $3^{2}$ (two-factor; three-level) experimental design. The concentrations of Guar gum $\left(\mathrm{X}_{1}\right)$ and the concentrations of RBW $\left(\mathrm{X}_{2}\right)$ were selected as independent variables (factors), which were varied at three levels (low, intermediate and high). Based on the preliminary trial batches, the levels of the three factors were chosen prior to the application of the factorial design.
The FLT (Y1), SI (Y2) and \% CDR (Y3) were selected as dependent variables (responses).

\subsection{Evaluation of gastroretentive tablets containing natural polymer and RBW using $3^{2}$ full factorial design}

The prepared tablets were evaluated for precompression and post-compression parameters [21-23].

\subsection{Optimization of formulation using $3^{2}$ factorial design} For optimization, effects of various independent variables upon measured responses and their interactions created by $3^{2}$ factorial design were represented using the following mathematical model equation:

$$
Y=b_{0}+b_{1} X_{1}+b_{2} X_{2}+b_{12} X_{1} X_{2}+b_{11} X_{12}+b_{22} X_{22}
$$

where $Y$ is represented as dependent variable, arithmetic mean response of the nine runs is indicated by $b_{0}$, and the estimated coefficient for the factor $X_{1}$ is $b_{1}$. The main effects $(X 1$ and $X 2)$ are the average result of change of one factor at a time from its low to high value. Change in response with the change in factors simultaneously is given by interaction terms $X_{1} X_{2}$. The polynomial terms $\left(X_{12}\right.$ and $\left.X_{22}\right)$ are included to investigate nonlinearity [30]. The significance of the model $(P<0.05)$ and individual response parameters were estimated employing oneway ANOVA.

\subsection{Statistical analysis and mathematical model fitting}

Statistical optimization was performed using DesignExpert 6.0.8 software (Stat-Ease Inc., USA). Rest of the data were analyzed using simple statistics.

The in vitro dissolution data were fitted to various mathematical models like zero-order, first-order, Higuchi, and Korsmeyer-Peppas models [31-34] for analyzing the mechanism of drug release from the tablets.

\subsection{Selection of optimized formulation and validation of mathematical models}

To validate the selected experimental design and polynomial equations, three optimum check points (formulation compositions) were chosen by intensive search performed over the entire experimental domain, and final formulation optimization was performed using a graphical optimization. The resultant experimental values were then quantitatively compared with predicted values. Formulation having maximum desirability value of $\% \mathrm{CDR}$, SI and FLT was found in the experimental region of the overlay plot which were selected as the optimized formulations. 
Table 2 Characterization of RBW

\begin{tabular}{ll}
\hline Parameters & Obtained Results \\
\hline Color & Yellowish white \\
Odor & Characteristics \\
Taste & Bland \\
Melting Point* & $78^{\circ} \mathrm{C}-82^{\circ} \mathrm{C}$ \\
Solubility & Hot alcohol, Benzene, Carbon tetrachloride, \\
& Ether, Chloroform, Isopropyl ether and insoluble \\
& in water \\
Saponification Value* & $80-85$ \\
Acid Value $^{*}$ & $13-16$ \\
lodine Value* & $18-22$ \\
Unsaponifiable Matter & $45 \%$ \\
\hline
\end{tabular}

*Values are the mean of three readings

\subsection{Stability study}

The stability studies were carried out following $\mathrm{ICH}$ guidelines. The optimized formulation was filled into the container and sealed packed. The studies were performed at $40 \pm 2{ }^{\circ} \mathrm{C}$ and $75 \pm 5 \%$ relative humidity $(\mathrm{RH})$ in the desiccators with saturated salt solution for up to 6 months [35].

\section{Results}

\subsection{Characterization of RBW}

The wax was characterized for various properties as per Pharmacopoeial guidelines (Table 2).

\subsection{Compatibility study}

Spectroscopic studies (FTIR) showed that there was no chemical interaction between the Famotidine (model drug) and the polymer as well as RBW (Fig. 1).

\subsection{Evaluation of gastroretentive tablets containing natural polymer, methocel K4M and RBW (preliminary trial batches)}

All the tablets passed test for weight variation, hardness, content uniformity and showed acceptable results with respect to drug content $(99.6 \pm 0.7)$ and $\%$ friability (Tables 3,4$)$.

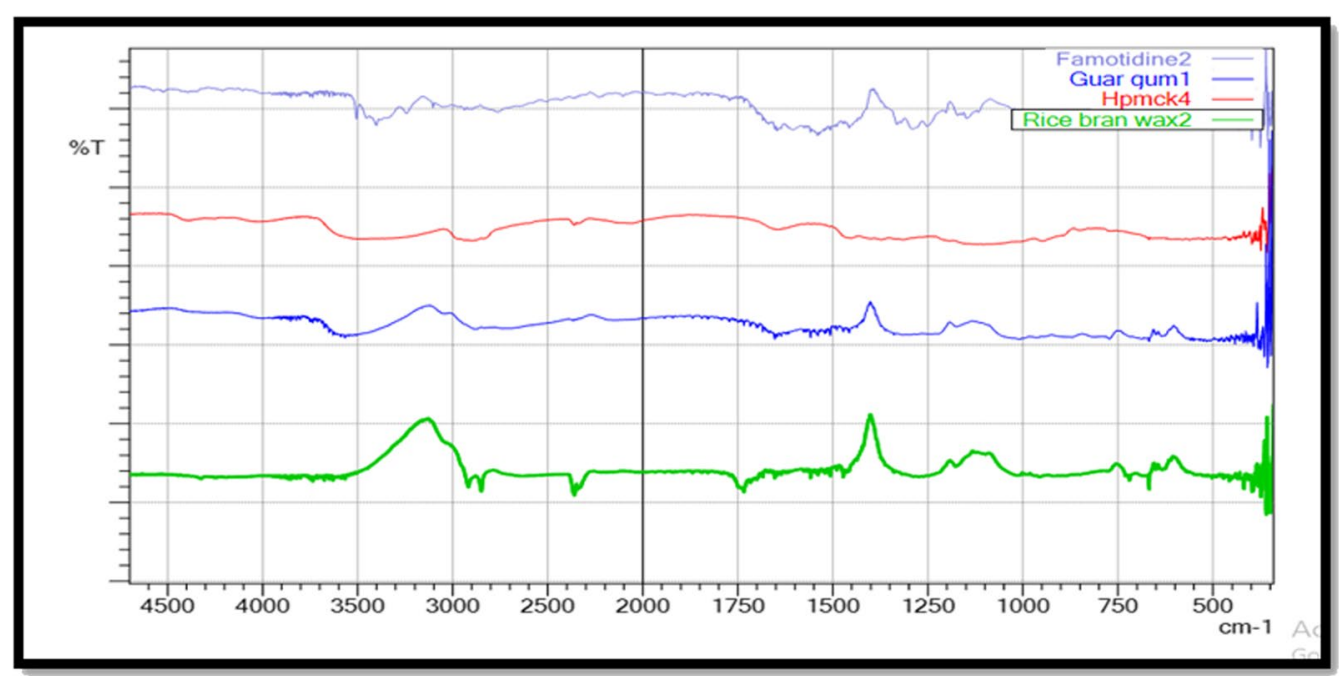

Fig. 1 Overlay spectrum of physical mixture of drug, polymer and gum

Table 3 Evaluation of pre compression parameters (HF1-HF3 and GF1-GF3)

\begin{tabular}{llllll}
\hline Formulation Code & $\begin{array}{l}\text { Loose bulk density } \\
\left(\mathbf{g m} / \mathbf{c m}^{\mathbf{3}}\right)^{*}\end{array}$ & $\begin{array}{l}\text { Tapped bulk density } \\
\left(\mathbf{g m} / \mathbf{c m}^{\mathbf{3}}\right)^{*}\end{array}$ & Hausner ratio $\mathbf{( H R})^{*}$ & Carr's index $(\mathbf{C l})^{*}$ & Angle of repose $\left(\boldsymbol{\theta}^{\circ}\right)^{*}$ \\
\hline HF1 & $0.39 \pm 0.05$ & $0.55 \pm 0.12$ & $1.41 \pm 0.19$ & $11.11 \pm 0.05$ & $0.58 \pm 0.02$ \\
HF2 & $0.44 \pm 0.05$ & $0.5 \pm 0.1$ & $1.15 \pm 0.35$ & $10.93 \pm 0.05$ & $0.39 \pm 0.02$ \\
HF3 & $0.33 \pm 0.01$ & $0.65 \pm 0.0$ & $1.9 \pm 0.13$ & $11.12 \pm 0.06$ & $0.52 \pm 0.03$ \\
GF1 & $0.55 \pm 0.05$ & $0.63 \pm 0.09$ & $1.22 \pm 0.19$ & $11.11 \pm 0.06$ & $0.51 \pm 0.03$ \\
GF2 & $0.52 \pm 0.05$ & $0.59 \pm 0.0$ & $1.13 \pm 0.11$ & $10.86 \pm 0.06$ & $0.51 \pm 0.05$ \\
GF3 & $0.44 \pm 0.06$ & $0.51 \pm 0.09$ & $1.17 \pm 0.34$ & $10.96 \pm 0.07$ & $0.46 \pm 0.03$ \\
\hline
\end{tabular}

*Values are expressed as mean \pm S.D., $n=3^{*}$ 
Table 4 Evaluation of post-compression parameters (HF1-HF3 and GF1-GF3)

\begin{tabular}{llccccc}
\hline Code & Dimension & & $\begin{array}{l}\text { Hardness } \\
\left(\mathbf{k g} / \mathbf{c m}^{2}\right)^{*}\end{array}$ & Friability $(\%)^{*}$ & $\begin{array}{l}\text { Weight variation } \\
(\%)^{*}\end{array}$ & $\begin{array}{l}\text { Drug content } \\
(\% \mathbf{w} / \mathbf{w})^{*}\end{array}$ \\
\cline { 2 - 6 } & Diameter $(\mathbf{m m})^{*}$ & Thickness $(\mathbf{m m})^{*}$ & & & & \\
\hline HF1 & $3.03 \pm 0.16$ & $6.1 \pm 0.21$ & $4.25 \pm 0.5$ & $0.310 \pm 0.01$ & $90.04 \pm 0.023$ & $19.08 \pm 0.05$ \\
HF2 & $3.03 \pm 0.16$ & $6.0 \pm 0.26$ & $4 \pm 0.5$ & $0.180 \pm 0.01$ & $95.43 \pm 0.017$ & $16.60 \pm 0.33$ \\
HF3 & $3.03 \pm 0.16$ & $6.06 \pm 0.24$ & $3.75 \pm 0.5$ & $0.624 \pm 0.03$ & $87.59 \pm 0.629$ & $10.36 \pm 0.05$ \\
GF1 & $3.03 \pm 0.16$ & $5.96 \pm 0.28$ & $4.5 \pm 0.5$ & $0.635 \pm 0.03$ & $75.51 \pm 0.011$ & $15.72 \pm 0.017$ \\
GF2 & $3.03 \pm 0.16$ & $6.0 \pm 0.14$ & $4.5 \pm 0.866$ & $0.565 \pm 0.03$ & $87.55 \pm 0.906$ & $19.23 \pm 0.017$ \\
GF3 & $3.03 \pm 0.16$ & $6.1 \pm 0.25$ & $4 \pm 0.28$ & $0.619 \pm 0.01$ & $95.43 \pm 0.663$ & $27.65 \pm 0.011$ \\
\hline
\end{tabular}

*Values are expressed as mean \pm S.D., $\mathrm{n}=3^{*}$

Table 5 In vitro buoyancy study (HF1- HF3 and GF1- GF3) and SI

\begin{tabular}{lccr}
\hline Formulation code & FLT $(\mathbf{s})^{*}$ & TFT $(\mathbf{h})^{*}$ & \multicolumn{1}{c}{ SI (\%)* } \\
\hline HF1 & $8 \pm 0.60$ & $>12$ & $65.38 \pm 0.003$ \\
HF2 & $12 \pm 0.88$ & $>12$ & $72.6 \pm 0.009$ \\
HF3 & $10 \pm 0.46$ & $>12$ & $84.8 \pm 0.009$ \\
GF1 & $15 \pm 0.43$ & $>12$ & $73.45 \pm 0.004$ \\
GF2 & $10 \pm 0.66$ & $>12$ & $88.85 \pm 0.006$ \\
GF3 & $12 \pm 0.07$ & $>12$ & $95.1 \pm 0.008$ \\
\hline
\end{tabular}

*Values are expressed as mean \pm S.D., $n=3^{*}$

\subsection{In vitro buoyancy}

The results for in vitro buoyancy, i.e., FLT and TFT are shown in Table 5. FLT for all the tablets was found less than one minute, and for all the tablets, TFT was found more than $12 \mathrm{~h}$.

\subsection{Swelling index (SI)}

The results of SI are shown in Table 5. A swelling study was performed on all the batches for $12 \mathrm{~h}$. SI was found to be in the range of $65 \%$ to $95 \%$.

\subsection{In vitro dissolution studies}

Cumulative percentage drug release (\% CDR) of batches (HF1-HF3 and GF1-GF3) is shown in Fig. 2. Drug release for HF1 to GF3 was found $94.32 \%$ to $99.71 \%$ for $12 \mathrm{~h}$.

\subsection{A $3^{2}$ full factorial design of experiment for gastroretentive tablets containing natural polymer and RBW}

In the present investigation, to study the effect of independent variables, i.e., the concentration of guar gum (X1), the concentration of RBW (X2) on dependent variables such as FLT, SI and \% CDR, a $3^{2}$ full factorial design

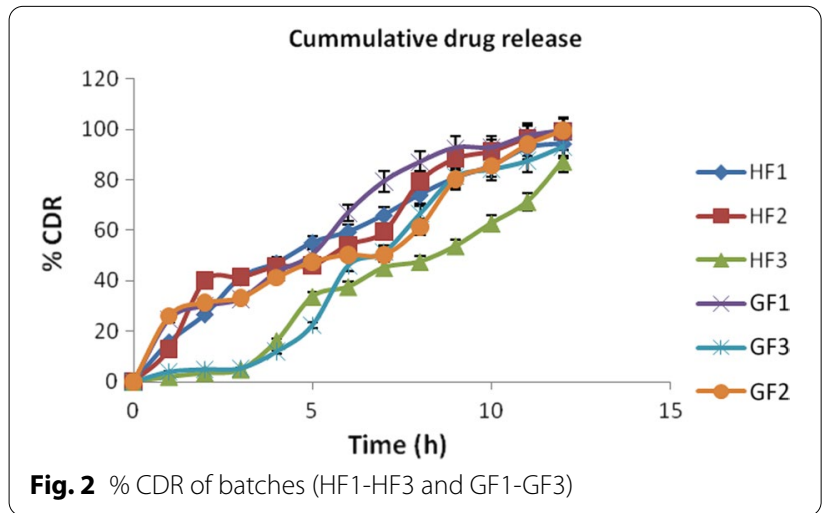

Table 6 A $3^{2}$ factorial design experimental layout

\begin{tabular}{lll}
\hline Formulation code & Guar Gum $(\mathbf{X} \mathbf{1})^{*}(\mathbf{m g})$ & RBW $(\mathbf{X} \mathbf{2})^{*}(\mathbf{m g})$ \\
\hline F1 & $20(-1)$ & $25(+1)$ \\
F2 & $30(+1)$ & $20(0)$ \\
F3 & $20(-1)$ & $20(0)$ \\
F4 & $20(-1)$ & $15(-1)$ \\
F5 & $30(+1)$ & $15(-1)$ \\
F6 & $25(0)$ & $15(-1)$ \\
F7 & $25(0)$ & $25(+1)$ \\
F8 & $30(+1)$ & $25(+1)$ \\
F9 & $25(0)$ & $20(0)$ \\
\hline
\end{tabular}

${ }^{*} \mathrm{X} 1$ and $\mathrm{X} 2$ represent the main effects (factors); $(+1)$ : higher value, $(0)$ : intermediate value and $(-1)$ : lower value. Actual values for X1: $30(+1), 25(0)$ and $20(-1)$; actual values for X2:25 (+1), $20(0)$ and $15(-1)$

was used based on the results of the preliminary trial batches.

All the dependent variables were found dependent on the selected independent variables as the wide variation was observed among the nine batches (F1 to F9). The high values of correlation coefficient $\left(R^{2}\right)$ for the dependent variables indicate a good fit. The experimental runs and their factor combinations are shown in Table 6. 
Table 7 Pre-compression parameters of batches (F1 to F9) using factorial design

\begin{tabular}{llllll}
\hline Formulation Code & $\begin{array}{l}\text { Loose bulk density } \\
\left(\mathbf{g m} / \mathbf{c m}^{\mathbf{3}}\right)^{*}\end{array}$ & $\begin{array}{l}\text { Tapped bulk density } \\
\left(\mathbf{g m} / \mathbf{c m}^{\mathbf{3}}\right)^{*}\end{array}$ & Hausner ratio $\mathbf{( H R})^{*}$ & Carr's index $(\mathbf{C l})^{*}$ & Angle of repose $\left.\boldsymbol{(}^{\circ}\right)^{*}$ \\
\hline F1 & $0.745 \pm 0.01$ & $0.838 \pm 0.00$ & $1.1248 \pm 0.01$ & $11.0978 \pm 0.06$ & $21.17 \pm 0.21$ \\
F2 & $0.732 \pm 0.01$ & $0.822 \pm 0.01$ & $1.1229 \pm 0.06$ & $10.9489 \pm 0.02$ & $21.19 \pm 0.58$ \\
F3 & $0.743 \pm 0.00$ & $0.836 \pm 0.01$ & $1.1251 \pm 0.08$ & $11.1244 \pm 0.12$ & $20.54 \pm 0.49$ \\
F4 & $0.743 \pm 0.02$ & $0.836 \pm 0.02$ & $1.1251 \pm 0.03$ & $11.124 \pm 0.18$ & $22.11 \pm 0.21$ \\
F5 & $0.732 \pm 0.00$ & $0.822 \pm 0.01$ & $1.1229 \pm 0.09$ & $10.9489 \pm 0.20$ & $20.82 \pm 0.11$ \\
F6 & $0.733 \pm 0.01$ & $0.823 \pm 0.02$ & $1.1227 \pm 0.04$ & $10.935 \pm 0.16$ & $20.29 \pm 0.21$ \\
F7 & $0.745 \pm 0.01$ & $0.838 \pm 0.00$ & $1.1248 \pm 0.03$ & $11.0978 \pm 0.15$ & $21.39 \pm 0.47$ \\
F8 & $0.732 \pm 0.01$ & $0.822 \pm 0.01$ & $1.1229 \pm 0.06$ & $10.9489 \pm 0.09$ & $20.59 \pm 0.50$ \\
F9 & $0.728 \pm 0.03$ & $0.817 \pm 0.01$ & $1.1222 \pm 0.02$ & $10.8935 \pm 0.08$ & $19.58 \pm 0.49$ \\
C1 ${ }^{a}$ & $0.751 \pm 0.02$ & $0.823 \pm 0.02$ & $1.0958 \pm 0.09$ & $8.74848 \pm 0.15$ & $23.24 \pm 0.18$ \\
C2 $^{a}$ & $0.746 \pm 0.01$ & $0.830 \pm 0.01$ & $1.1126 \pm 0.10$ & $10.1204 \pm 0.21$ & $24.32 \pm 0.11$ \\
C3 $^{a}$ & $0.741 \pm 0.07$ & $0.825 \pm 0.04$ & $1.113 \pm 0.60$ & $10.1818 \pm 0.26$ & $22.48 \pm 0.21$ \\
\hline
\end{tabular}

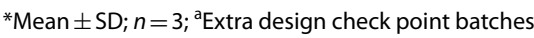

Table 8 Post-compression parameters of batches (F1 to F9) using factorial design

\begin{tabular}{|c|c|c|c|c|c|c|}
\hline Code & Diameter $(\mathrm{mm})^{* *}$ & Thickness $(\mathrm{mm})^{* *}$ & Hardness $\left(\mathrm{kg} / \mathrm{cm}^{2}\right)^{*}$ & Friability (\%)* & $\begin{array}{l}\text { Weight } \\
\text { variation (\%) }\end{array}$ & Drug content (\%w/w) \\
\hline F1 & $9.0 \pm 0.0$ & $3.18 \pm 0.14$ & $5.8 \pm 0.25$ & $0.41 \pm 0.05$ & \pm 2.11 & $99.81 \pm 1.4$ \\
\hline F2 & $9.0 \pm 0.0$ & $3.16 \pm 0.12$ & $5.7 \pm 0.27$ & $0.31 \pm 0.08$ & \pm 2.16 & $99.67 \pm 1.7$ \\
\hline F3 & $9.0 \pm 0.0$ & $3.15 \pm 0.12$ & $5.5 \pm 0.44$ & $0.36 \pm 0.03$ & \pm 2.02 & $98.75 \pm 0.5$ \\
\hline F4 & $9.0 \pm 0.0$ & $3.28 \pm 0.11$ & $5.6 \pm 0.41$ & $0.37 \pm 0.01$ & \pm 2.75 & $99.47 \pm 1.3$ \\
\hline F5 & $9.0 \pm 0.0$ & $3.13 \pm 0.10$ & $5.7 \pm 0.27$ & $0.36 \pm 0.08$ & \pm 2.46 & $99.87 \pm 0.5$ \\
\hline F6 & $9.0 \pm 0.0$ & $3.23 \pm 0.16$ & $5.8 \pm 0.62$ & $0.28 \pm 0.06$ & \pm 1.85 & $98.38 \pm 0.8$ \\
\hline F7 & $9.0 \pm 0.0$ & $3.18 \pm 0.14$ & $5.8 \pm 0.37$ & $0.41 \pm 0.03$ & \pm 1.89 & $97.01 \pm 1.7$ \\
\hline F8 & $9.0 \pm 0.0$ & $3.21 \pm 0.14$ & $5.7 \pm 0.44$ & $0.36 \pm 0.12$ & \pm 1.86 & $99.24 \pm 0.6$ \\
\hline F9 & $9.0 \pm 0.0$ & $3.20 \pm 0.16$ & $5.4 \pm 0.27$ & $0.22 \pm 0.06$ & \pm 3.75 & $99.04 \pm 0.1$ \\
\hline $\mathrm{C}^{\mathrm{a}}$ & $9.0 \pm 0.0$ & $3.19 \pm 0.12$ & $5.9 \pm 0.11$ & $0.32 \pm 0.14$ & \pm 2.30 & $98.90 \pm 0.14$ \\
\hline$C 2^{\mathrm{a}}$ & $9.0 \pm 0.0$ & $3.24 \pm 0.23$ & $5.6 \pm 0.23$ & $0.39 \pm 0.02$ & \pm 2.29 & $99.07 \pm 0.13$ \\
\hline$C 3^{\mathrm{a}}$ & $9.0 \pm 0.0$ & $3.22 \pm 019$ & $5.8 \pm 016$ & $0.29 \pm 0.11$ & \pm 3.12 & $99.71 \pm 0.51$ \\
\hline
\end{tabular}

${ }^{*}$ Mean $\pm S D ; n=3 ;{ }^{a}$ Extra design check point batches

\subsection{Evaluation of gastroretentive tablets containing natural polymer and RBW using $3^{2}$ full factorial design} Gastroretentive tablets were evaluated for pre- and postcompression parameters and results are shown in Tables 7 and 8 . All the tablets passed test for weight variation, hardness, content uniformity and showed acceptable results with respect to drug content $(99.87 \pm 0.5)$ and \% friability.

\subsection{Evaluation of gastroretentive tablets containing natural polymer and RBW using $3^{2}$ full factorial design for FLT, SI and \%CDR}

The FLT, SI and \% CDR of F1 to F9 along with the three extra check point formulations are shown in Table 9 and Figs. 3, 4 and 5 .
The total FLT of all the formulations was within the limits (less than three minutes). The SI of the formulations $\mathrm{F} 1$ to $\mathrm{F} 9$ and extra check point formulations $\mathrm{C} 1-\mathrm{C} 3$ was evaluated where the highest and lowest swelling was observed with the formulation F7 and F1 after $12 \mathrm{~h}$. The drug release was found to be retarded for $12 \mathrm{~h}$.

Formulations containing low level of polymer showed higher drug release $(94.21 \pm 0.57$ to $98.28 \pm 0.48 \%)$ than the formulations containing high level of polymer that showed drug release $87.59 \pm 0.39$ to $89.68 \pm 0.26 \%$ at $12 \mathrm{~h}$ which may be due to increased viscosity offered by gelling of hydrophilic polymer. 
Table 9 Factorial design and their observed response values in gastroretentive tablets

\begin{tabular}{|c|c|c|c|c|c|}
\hline \multirow[t]{2}{*}{ Formulation code } & \multirow{2}{*}{$\begin{array}{l}\text { Guar Gum (mg) } \\
(\mathrm{X} 1=\mathrm{A})\end{array}$} & \multirow{2}{*}{$\begin{array}{l}\text { RBW }(\mathrm{mg}) \\
(\mathrm{X} 2=\mathrm{B})\end{array}$} & \multicolumn{3}{|c|}{ Responses* } \\
\hline & & & FLT (s) & SI & $\% C D R$ \\
\hline F1 & $20(-1)$ & $25(+1)$ & $10 \pm 1.154$ & $79.63 \pm 0.22$ & $94.21 \pm 0.57$ \\
\hline F2 & $30(+1)$ & $20(0)$ & $10 \pm 3.60$ & $80.48 \pm 0.55$ & $89.68 \pm 0.26$ \\
\hline F3 & $20(-1)$ & $20(0)$ & $15 \pm 2.51$ & $82.31 \pm 1.21$ & $96.24 \pm 0.85$ \\
\hline $\mathrm{F} 4$ & $20(-1)$ & $15(-1)$ & $15 \pm 1.73$ & $86.62 \pm 0.20$ & $98.28 \pm 0.48$ \\
\hline F5 & $30(+1)$ & $15(-1)$ & $20 \pm 2.88$ & $88.01 \pm 0.28$ & $87.59 \pm 0.39$ \\
\hline F6 & $25(0)$ & $15(-1)$ & $20 \pm 2.88$ & $88.63 \pm 0.375$ & $86.89 \pm 0.37$ \\
\hline F7 & $25(0)$ & $25(+1)$ & $22 \pm 2.51$ & $90.31 \pm 0.739$ & $85.53 \pm 0.41$ \\
\hline F8 & $30(+1)$ & $25(+1)$ & $25 \pm 10.40$ & $85.02 \pm 0.49$ & $88.86 \pm 0.43$ \\
\hline F9 & $25(0)$ & $20(0)$ & $27 \pm 2.47$ & $89.68 \pm 1.36$ & $88.98 \pm 0.51$ \\
\hline $\mathrm{C}^{\mathrm{a}}{ }^{\mathrm{a}}$ & 19.75 & 14.92 & $28 \pm 1.23$ & $82 \pm 1.21$ & $94.20 \pm 0.32$ \\
\hline$C 2^{\mathrm{a}}$ & 24.85 & 19.64 & $27 \pm 2.30$ & $80.89 \pm 1.34$ & $89.30 \pm 0.63$ \\
\hline$C 3^{\mathrm{a}}$ & 29.80 & 24.78 & $28 \pm 2.0$ & $88.96 \pm 1.82$ & $92.24 \pm 0.75$ \\
\hline
\end{tabular}

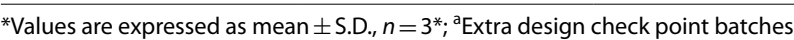

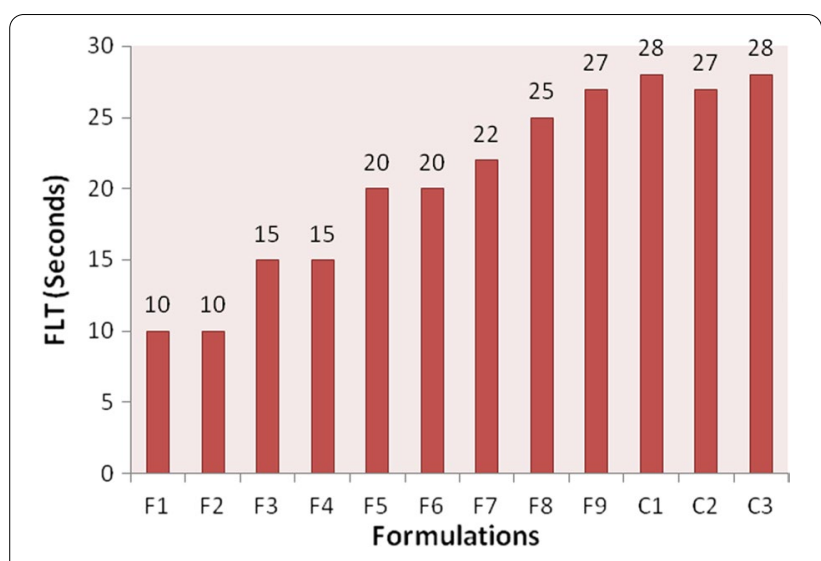

Fig. 3 FLT of gastroretentive formulations

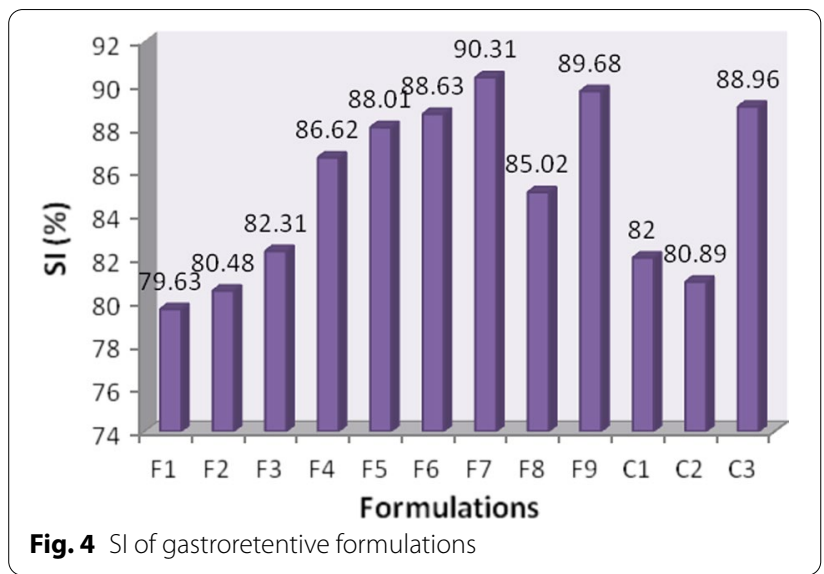

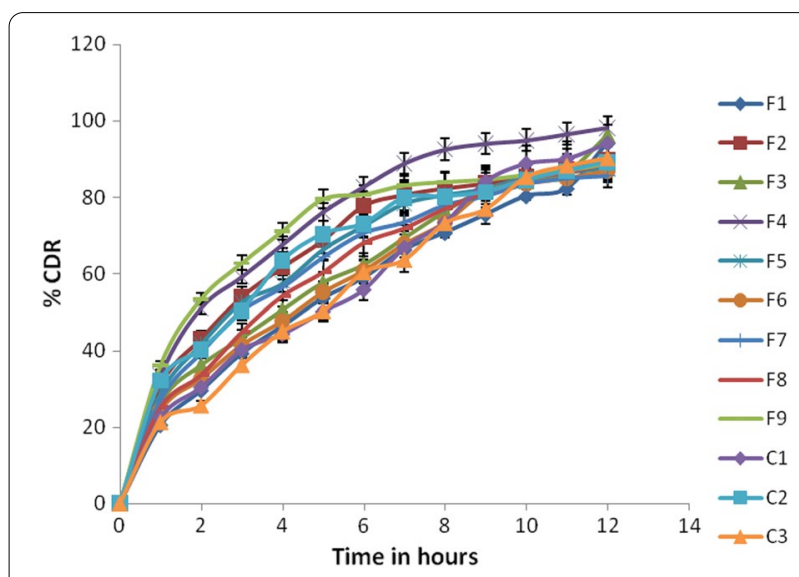

Fig. 5 In vitro drug release profile of gastroretentive formulations along with extra check point formulations

\subsection{Kinetic analysis of the drug release data}

To analyze the mechanism of drug release from the tablets, the in vitro dissolution data (Fig. 5) were fitted to various mathematical models like zero-order, first-order, Higuchi, and Korsmeyer-Peppas models (Table 10).

\subsection{Statistical analysis and mathematical model fitting}

As per the $3^{2}$ factorial design, different trial formulations of gastroretentive tablets were prepared by melt granulation method. Overview of the experimental trial and observed responses is shown in Table 8. The models were 
Table 10 Model fitting of gastroretentive tablets (F1-F9)

\begin{tabular}{lllll}
\hline Batch No & \multicolumn{3}{l}{ Regression coefficient } & \\
\cline { 2 - 5 } & $\begin{array}{l}\text { Zero- } \\
\text { order } \\
\text { kinetics }\end{array}$ & $\begin{array}{l}\text { First-order } \\
\text { kinetics }\end{array}$ & Higuchi kinetics & $\begin{array}{l}\text { Krosmeyer- } \\
\text { Peppas }\end{array}$ \\
\hline F1 & 0.9787 & 0.8691 & 0.8398 & 0.4928 \\
F2 & 0.9666 & 0.5806 & 0.9511 & 0.4859 \\
F3 & 0.9885 & 0.6454 & 0.8443 & 0.5018 \\
F4 & 0.9757 & 0.5620 & 0.9103 & 0.4268 \\
F5 & 0.9707 & 0.8963 & 0.8126 & 0.4153 \\
F6 & 0.9683 & 0.5858 & 0.8821 & 0.4858 \\
F7 & 0.9906 & 0.9693 & 0.9988 & 0.5988 \\
F8 & 0.9766 & 0.7970 & 0.8979 & 0.4979 \\
F9 & 0.9649 & 0.8978 & 0.7949 & 0.6949 \\
C1 $^{\text {a }}$ & 0.9769 & 0.9021 & 0.9139 & 0.5428 \\
C2 $^{\text {a }}$ & 0.9843 & 0.7989 & 0.8946 & 0.6231 \\
C3 $^{\text {a }}$ & 0.9898 & 0.8648 & 0.9010 & 0.5963 \\
\hline
\end{tabular}

${ }^{\mathrm{a}}$ Extra design check point batches

Table 11 Statistical analysis of generated models

\begin{tabular}{lllll}
\hline Response & F value & $\boldsymbol{P}$ value & $\boldsymbol{R}^{\mathbf{2}}$ value & $\begin{array}{l}\text { Adequate } \\
\text { precision }\end{array}$ \\
\hline FLT (Y1) & 5.44 & 0.0365 & 0.8657 & 3.849 \\
$\mathrm{SI}(\mathrm{Y} 2)$ & 6.53 & 0.0429 & 0.903 & 0.114 \\
\% CDR (Y3) & 8.26 & 0.021 & 0.892 & 0.840 \\
\hline
\end{tabular}

found significant for all response parameters as indicated by ANOVA. Table 11 shows the $\mathrm{F}$ and $\mathrm{P}$ value for the responses using factorial design along with the percentage predicted errors for the trial formulations.

The effects of the independent variables (factors) on each investigated response are shown in Fig. 6 (a-f) as three-dimensional response surface plots and contour plots. The three-dimensional response surface plots relating FLT, SI and \% CDR indicated the lessen values of FLT and \% CDR and increased values of SI with the rise of guar gum and RBW.

From the predicted and experimental values (Table 12), it was observed that the lower magnitude of error as well as the significant value of $R^{2}(0.9977)$ in the current study indicated a high prognostic ability of formulation with the use of response surface methodology.

\subsection{Stability studies}

From the stability studies of the optimized gastroretentive tablet formulation (C3), it was observed that there was no considerable change in FLT, SI and \% CDR which proved the stability of the formulation.

\section{Discussion}

It was concluded from the study that swelling increased with time as the polymer gradually absorbs water due to its hydrophilicity. The hydrophilic polymer in the outermost layer hydrates and swells to form a gel barrier.

FLT was found to increase with the increase in the concentration of polymer and RBW. The SI was found to increase with the increase in the concentration of polymer and also due to hydrophilic nature of the polymer. In all the formulations, good matrix integrity was observed.

It was observed that formulations containing high level of polymer and RBW exhibited delayed drug release indicating better matrix characteristics.

It was observed that the release profile fitted best to zero-order equation with non-Fickian diffusion mechanism of drug release which demonstrates swelling-controlled drug release mechanism.

Design Expert software gave suitable polynomial model equations involving individual main factors and interaction factors after fitting these data. The model equations relating FLT, SI and \% CDR as responses by eliminating nonsignificant terms $(P>0.05)$ are

$$
\begin{aligned}
& \mathrm{FLT}=+8.75-0.25 * A+1.25 * B+2.25 * A * B \\
& {\left[R^{2}=0.8657 ; F \text {-value }=5.44 ; P<0.05\right]} \\
& \mathrm{SI}=+86.25+0.25 * A-2.25 * B+3.75 * A * B \\
& {\left[R^{2}=0.903 ; F \text {-value }=6.53 ; P<0.05\right]} \\
& \% \mathrm{CDR}=83.00+0.50 * A-3.00 * B+4.50 * A * B \\
& {\left[R^{2}=0.892 ; F \text {-value }=8.26 ; P<0.05\right]}
\end{aligned}
$$

Each response coefficient was studied for its statistical significance and the relationship between the variables was further elucidated by using the response surface plot and contour plot. Ratio of 3.849 (FLT), 0.114 (SI) and 0.840 (\% CDR) indicated an adequate signal. All the variables had $P$ value less than $0.05(P<0.05)$ which is considered as significant.

Three formulations having maximum desirability value of FLT, \% SI and \% CDR were found in the experimental region of the overlay plot which were selected for the optimization of formulations. Based on maximum desirability values of FLT, SI and \% CDR, formulation C3 was selected as final optimized formulation from the three formulations.

\section{Conclusions}

The present investigation aimed at formulation and evaluation of gastroretentive tablets based on combination of natural polymer and RBW containing Famotidine as a 


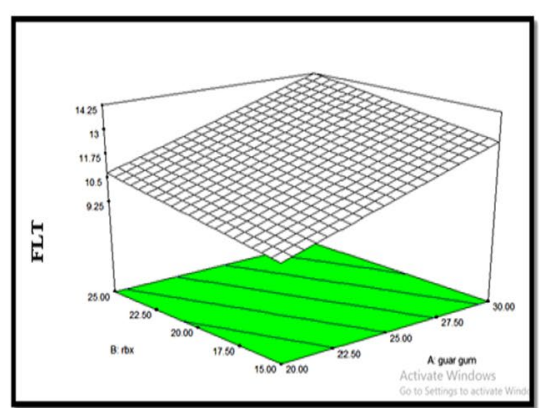

(a)

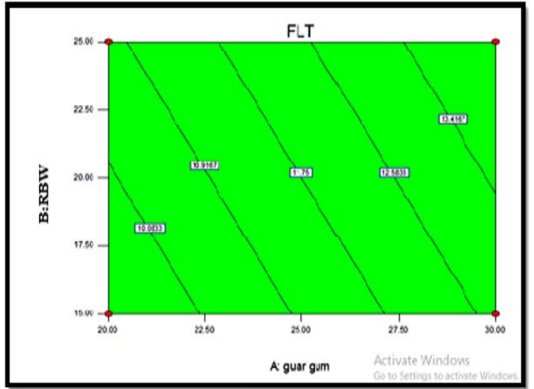

(d)

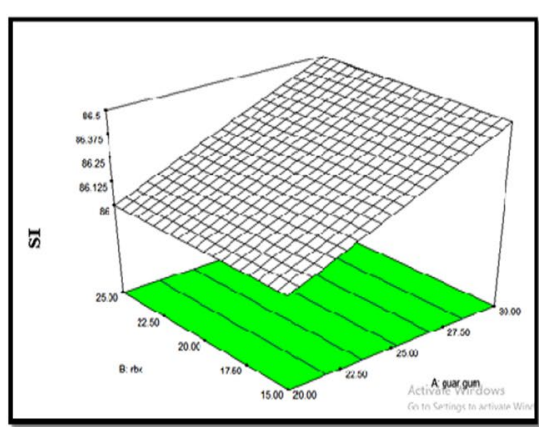

(b)

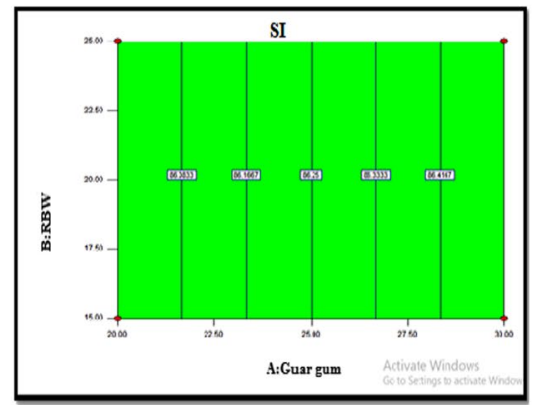

(e)

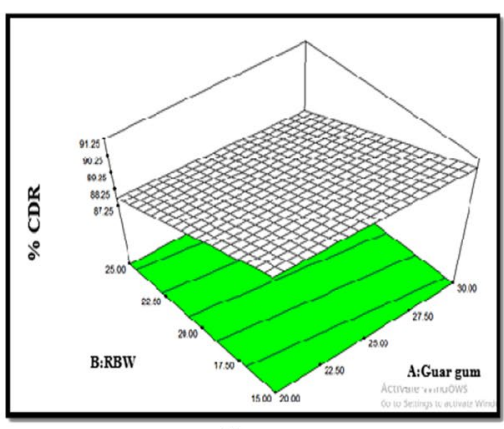

(c)

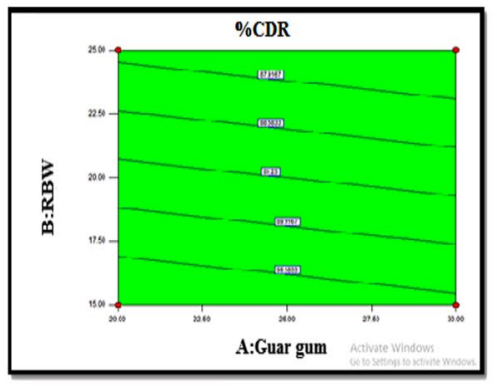

(i)

Fig. 6 Three-dimensional response surface plots $(\mathbf{a}-\mathbf{c})$ and contour plots $(\mathbf{d}-\mathbf{f})$ relating FLT, SI and \% CDR

Table 12 Check point formulations and \% Error

\begin{tabular}{|c|c|c|c|c|c|c|}
\hline \multirow[t]{2}{*}{ Batch Code } & \multicolumn{2}{|c|}{ Composition } & \multirow[t]{2}{*}{ Responses* } & \multirow[t]{2}{*}{ Predicted Value } & \multirow[t]{2}{*}{ Experimental Value } & \multirow[t]{2}{*}{$\%$ Error } \\
\hline & $\mathrm{X} 1^{*}$ & $\mathrm{X} 2^{*}$ & & & & \\
\hline \multirow[t]{3}{*}{$\mathrm{C} 1$} & 30 & 25 & $Y_{1}$ & 15.00 & 11.44 & 3.56 \\
\hline & & & Y2 & 82.65 & 82.31 & 0.34 \\
\hline & & & Y3 & 70.19 & 70.14 & 0.05 \\
\hline \multirow[t]{3}{*}{ C2 } & 20 & 20 & Y1 & 12.00 & 11.44 & 0.56 \\
\hline & & & Y2 & 88.16 & 88.63 & 0.47 \\
\hline & & & Y3 & 70.14 & 70.09 & 0.05 \\
\hline \multirow[t]{3}{*}{ C3 } & 25 & 20 & Y1 & 10.00 & 11.44 & 1.44 \\
\hline & & & Y2 & 78.74 & 79.63 & 0.89 \\
\hline & & & Y3 & 92.93 & 90.03 & 2.9 \\
\hline
\end{tabular}

*X1-Guar Gum; X2-RBW; Y1-FLT;Y2-SI;Y3-\% CDR

model drug. The results of compatibility study indicated the compatibility of selected excipients with the drug. All the tablets passed test for weight variation, hardness, content uniformity and showed acceptable results with respect to drug content $(99.6 \pm 0.7)$ and \% friability in the preliminary trial batches using various polymers like hydroxypropyl methyl cellulose (HPMC), ethyl cellulose, guar gum and RBW. FLT for all the tablets was found less than one minute and for all the tablets TFT was found more than $12 \mathrm{~h}$. It was concluded from the SI study that, swelling increased with time as the polymer gradually absorbs water due to its hydrophilicity. Drug release for HF1 to GF3 was found $94.32 \%$ to $99.71 \%$ for $12 \mathrm{~h}$. In the present investigation, to study the effect of independent variables, i.e., the concentrations of guar gum (X1), the concentrations of RBW (X2) on dependent variables such as FLT, SI and \% CDR, a $3^{2}$ full factorial design was used based on the results of the preliminary trial batches.

The high values of correlation coefficient $\left(R^{2}\right)$ for the dependent variables indicate a good fit. All the tablets 
passed test for weight variation, hardness, content uniformity and showed acceptable results with respect to drug content $(99.87 \pm 0.5)$ and $\%$ friability. The total FLT of all the formulations was within the limits (less than three minutes). FLT was found to increase with the increase in the concentration of polymer and RBW. In all the formulations, good matrix integrity was observed and drug release was found retarded for $12 \mathrm{~h}$. Formulations containing low level of polymer showed higher drug release $(94.21 \pm 0.57$ to $98.28 \pm 0.48 \%)$ than the formulations containing high level of polymer that showed drug release $87.59 \pm 0.39$ to $89.68 \pm 0.26 \%$ at $12 \mathrm{~h}$ which may be due to increased viscosity offered by gelling of hydrophilic polymer. It was concluded that the release profile fitted best to zero-order equation with non-Fickian diffusion mechanism of drug release which demonstrates swelling-controlled drug release mechanism. The models were found significant for all response parameters as indicated by ANOVA. The three-dimensional response surface plots relating FLT, SI and \% CDR indicated the decreased values of FLT and \% CDR and increased values of SI with the increment in guar gum and RBW. Out of the three check point formulations, C3 was selected as final optimized formulation based on maximum desirability values of FLT, SI and \% CDR. Stability studies proved the stability of the formulation. Thus, gastroretentive tablets were formulated successfully to control the drug delivery with the help of natural polymer and RBW.

\section{Abbreviations}

GIT: Gastrointestinal tract; GRDDS: Gastroretentive drug delivery system; RBW: Rice bran wax; FLT: Floating lag time; TFT: Total floating time; SI: Swelling index \%CDR: Cumulative percentage drug release; h: Hour; $R^{2}$ : Correlation coefficient; ANOVA: Analysis of variance; HPMC: Hydroxypropyl methyl cellulose.

\section{Acknowledgements}

The authors express their gratitude to the Principal and President of Dadasaheb Balpande College of Pharmacy, Besa for providing the facilities to carry out the research work.

\section{Authors' contributions}

VPS involved in conceptualization, supervision and writing-original draft preparation. GGG involved in methodology, investigation and analysis. All authors read and approved final manuscript.

\section{Funding}

None.

Availability of data and materials

All data generated or analyzed during this study are included in the article.

\section{Declarations}

Ethics approval and consent to participate

Not applicable.

\section{Consent for publication}

Not applicable.

\section{Competing interests}

Authors declare no competing interests.

Received: 29 October 2021 Accepted: 20 December 2021

Published online: 06 January 2022

\section{References}

1. Patel SS, Ray S, Thakur RS (2006) Formulation and evaluation of floating drug delivery system containing clarithromycin for Helicobacter pylori. Acta Pol Pharm 63:53-61

2. Homayun B, Lin X, Choi HJ (2019) Challenges and recent progress in oral drug delivery systems for biopharmaceuticals. Pharmaceutics 11(3):129

3. Streubel A, Siepmann J, Bodmeier R (2006) Gastroretentive drug delivery system. Expert Opin Drug Deliv 3(2):217-233

4. Brahma NS, Kwon HK (2000) Floating drug delivery systems: an approach to oral controlled drug delivery via gastric retention. J Control Release 63:235-259

5. Khar RK, Vyas SP (2012) Controlled drug delivery-concepts and advances. CBS Publishers and Distributors, New Delhi

6. Shakya R, Thapa P, Saha RN (2013) In vitro and in vivo evaluation of gastroretentive floating drug delivery system of ofloxacin. Asian J Pharm Sci 8(3):191-198

7. Bardonnet PL, Faivre V, Pugh WJ, Piffaretti JC (2006) Gastroretentive dosage forms: overview and special case of Helicobacter pylori. J Control Release 111:1-18

8. Echizen H, Ishizaki T (1991) Clinical pharmacokinetics of Famotidine. Clin Pharmacokinet 21(3):178-194

9. Jaimini M, Rana AC, Tanwar YS (2007) Formulation and evaluation of famotidine floating tablets. Curr Drug Deliv 4:51-55

10. Rana V, Rai P, Tiwary AK, Singh RS (2011) Modified gums: approaches and applications in drug delivery. Carbohydr Polym 83:1031-1047

11. Whistler RL, Hymowitz T (1979) Guar: agronomy, production, industrial use, and nutrition. Purdue University Press, West Lafayette

12. Casas JA, Mohedano AF, Garci'a-Ochoa F, (2000) Viscosity of guar gum and xanthan/guar gum mixture solutions. J Sci Food Agric 80(12):1722-1727

13. Mudgil D, Barak S, Khatkar BS (2014) Guar gum: processing, properties and food applications-a review. J Food Sci Technol 51:409-418

14. Cheetham NWH, Mashimba ENM (1990) Conformational aspects of xanthan-galactomannan gelation. Further evidence from optical-rotation studies. Carbohydr Polym 14:17-27

15. Brosio E, Dubado A, Verzegnassi B (1994) Pulsed field gradient spin-echo NMR measurement of water diffusion coefficient in thickening and gelling agents: guar galactomannan solutions and pectin gels. Cell Mol Biol 40:569-573

16. Houston DF (1972) Rice chemistry and technology, 2nd edn. AACC, St Paul

17. Gunawan S, Vali SR, Ju YS (2006) Purification and identification of rice bran oil fatty acid steryl and wax esters. J Am Oil Chem Soc 83(5):449-456

18. Sabale VP, Sabale PM, Lakhotiya CL (2007) In vitro studies on rice bran wax as skin moisturizer. Indian J Pharm Sci 69(2):215-218

19. Pharmacopoeia of India (1966) Govt. of India, New Delhi.

20. Prajapati PH, Nakum W, Patel CN (2012) Formulation and evaluation of floating matrix tablet of stavudine. Int J Pharm Investig 2(2):83-89

21. British Pharmacopoeia (2000) Vol.2, 3rd edn. Her majesty's stationary office for the department of health, London

22. Charyulu NR, Patil AB, Lakshmi Deepika CH, Prabhu P, Shastry CS (2011) Development of gastro retentive floating matrix tablets of Diltiazem Hydrochloride. NUJHS 1:38-45

23. Skoog DA, Holler F (2007) Principles of instrumental analysis, 6th edn. Thomson Asia Pvt Limited, Singapore

24. Khan F, Shaikhul MIB, Khan ZR, Azam KR, Sadat SMA, Reza MS (2008) Preparation and in vitro evaluation of theophyline loaded gastroretentive floating tablets of Methocel K4M. Dhaka Univ J Pharm Sci 7(1):65-70

25. Gharti KP, Thapa P, Budhathoki U, Bhargava A (2012) Formulation and in vitro evaluation of floating tablets of hydroxypropyl methylcellulose and polyethylene oxide using ranitidine hydrochloride as a model drug. J Young Pharm 4(4):201-208 
26. Havaldar VD, Kulkarni AS, Dias RJ, Aloorkar NH, Mali KK (2009) Floating matrix tablets of atenolol: formulation and in vitro evaluation. Asian J Pharm 3(4):286-291

27. Pawar HA, Gharat PR, Dhavale RV, Joshi PR, Rakshit PP (2013) Development and evaluation of gastroretentive floating tablets of an antihypertensive drug using hydrogenated cottonseed oil. ISRN Pharm 2013:1-9

28. Nemade MS, Thorat SS, Chaudhari RY, Pati VR (2014) Formulation development of controlled release drug delivery system for tegaserod maleate. Res J Pharm and Tech 7(9):1046-1051

29. Mulye NV, Turco SJ (1996) An examination of assumptions underlying the first-order kinetic model for release of water soluble drugs from dicalcium phosphate dihydrate matrices. Drug Dev Ind Pharm 22(7):673-679

30. Singh B, Kapil R, Nandi M, Ahuja N (2011) Developing oral drug delivery systems using formulation by design: vital precepts, retrospect and prospects. Expert Opin Drug Deliv 8(10):1341-1360

31. Varelas CG, Dixon DG, Steiner CA (1995) Zero-order release from biphasic polymer hydrogels. J Control Release 34(3):185-192

32. Fu Y, Kao WJ (2010) Drug release kinetics and transport mechanisms of nondegradable and degradable polymeric delivery systems. Expert Opin Drug Deliv 7(4):429-444

33. Higuchi T (1961) Rate of release of medicaments from ointment bases containing drugs in suspension. J Pharm Sci 50:874-875

34. Korsmeyer RW, Gurny R, Doelker E, Buri P, Peppas NA (1983) Mechanisms of solute release from porous hydrophilic polymers. Int J Pharm 15(1):25-35

35. ICH: Q1A (R2): Stability testing of new drug substances and drug products https://www.ema.europa.eu/en/documents/scientific-guideline/ ich-q-1-r2-stability-testing-new-drug-substances-products-step-5_en. pdf. Accessed 26 April 2018

\section{Publisher's Note}

Springer Nature remains neutral with regard to jurisdictional claims in published maps and institutional affiliations.

\section{Submit your manuscript to a SpringerOpen ${ }^{\ominus}$ journal and benefit from:}

- Convenient online submission

- Rigorous peer review

- Open access: articles freely available online

- High visibility within the field

- Retaining the copyright to your article

Submit your next manuscript at $\boldsymbol{\nabla}$ springeropen.com 